\title{
Analysis of Writing Motivation for Medical University EFL Learners in China
}

\author{
Yingying Ma \\ School of Foreign Languages, Zunyi Medical University, Zunyi, China
}

\begin{abstract}
This research aims to investigate EFL learners' writing motivation in a medical university. Although writing plays a critical role in English learning, it has often been neglected by students, they only take writing as a tortured task which has been related to the score in final tests. In a medical university, most students are afraid of writing and lack motivation to write in English because of the heavy load and pressure from their medical tasks. Therefore, this study describes students' writing motivation through the class observation, questionnaire, and interview, and finds what factors affect students' writing motivation. Based on the analysis results, combined with features of students from a medical university, the researcher comes up with strategies to improve learners' writing motivation.
\end{abstract}

Index Terms —English writing, motivation factors, EFL learners

\section{INTRODUCTION}

\section{A. Background}

Writing is an indispensable part of language learning while it is often regarded as the most difficult part in second language acquisition. The current situation of English writing instruction is far from satisfactory because of demotivators for college students on writing. How to enhance students' motivation becomes an urgent project for language researchers. Wen (1996) claimed that English writing ability could be the most important standard to judge whether or not a writing teacher is qualified for her teaching. Qing (2002) pointed out that English writing was an unfrequented and neglected area for a long time. However, Dornyei (2015) held the view that research in ESL composition has important ramifications for the teaching of writing in the ESL classroom. Since students' writing motivation could be stimulated by teachers, a large number of relevant studies could be carried out to improve teachers' teaching and facilitate students' learning. These studies were conducted from various aspects. Hui \& Ma (2016) addressed problems existing in students' writing and teaching. Yu \& Lee (2016) focused on the function of teachers' feedback. Ma (2005) examined on students' motivation and engagement in EFL writing context. Ren (2018) developed the investigated factors which could influence students' motivation in writing.

\section{B. Motivation}

Motivation refers to an individual's choice of a particular action, the persistence with it, and the effort put on it (Dornyei, 2001, P. 8; Manolopoulou-Sergi, 2004, p. 428). Motivation, as an inner psychological factor, consists of psychological, private, and unobservable factors (Ainley, 2012; Reeve, 2012), which can stimulate the desire to take actions and lead to the learners' achievement. Motivation is understood to be a crucial factor in language learning (whether in native, ESL, or EFL contexts), playing an essential role in engaging students in learning activities (Dornyei, 2001). Motivation is therefore a potentially key variable in predicting language learning outcomes (Dornyei, 2005). There are two kinds of motivation: intrinsic motivation and extrinsic motivation. Intrinsic motivation occurs when someone is willing to work on a task even if he is aware that there is not any reward for it. While extrinsic motivation occurs when someone embarks on a task for a certain purpose or rewards. In China, many researchers define "motivation" in various ways. Wen (1996) defines motivation as an effort to learn English. Ma (2005) believes that motivation is stimulated by psychological factors such as interests, expectations, goals.

Although research on motivation or writing has proliferated in recent years, little attention has been paid to writing motivation including the relationship between motivation and writing results, factors to affect writing motivation, and so on. Due to the increasing importance of L2 writing for university students, a large number of L2 writing programs, curricula, and courses have been established to enhance students' writing proficiency and skills. Dornyei (2003) points out that students' behavior in working on a task is triggered by the combination of generalized and specific motivations and is related to specific characteristics of a writing task. The purpose of this study is to survey medical students' English writing motivation and to explore the factors that may have an impact on the motivation.

\section{RESEARCH DESIGN}

\section{A. Research Overview}

This research aims at pursuing answers for the following two questions: 
(1) What is the English writing motivation for medical students?

(2) What factors could influence students' writing motivation?

\section{B. Participants}

According to Strayer (2012), in order to get objective and persuasive results, the participants should be selected randomly, and the norm of procedures should be set in the quantitative research to decrease the influence brought by external factors.

The admission grades for students vary from major to major, so we only choose clinical majors as our subjects to ensure the validity of this study. The participants in this study are 128 second-year clinical majors (two classes) from Zunyi Medical University, 70 are boys and 58 are girls. The reason for choosing clinical majors is that their English proficiency level is more homogeneous than other majors in the university, and all of them shoulder the pressure from their medical courses. For the second-year students, they have been familiar with their teachers' writing instruction and have been exposed to the instruction for more than one year. These two factors made it easier for the researcher to elicit the students' writing motivation. Sophomores have already participated in CET-4 and some of them should prepare for CET-6, so they have to spend more time in learning English, and English writing is of course included.

\section{Class Observation}

Class observation can provide researchers with insights into what actually occurred in reading classes. The aim of class observation is to give instructions based on problems in teaching practice. There are two aspects researchers should note when observing a class. On the one hand, researchers should record potential factors that may lead to the change of students' writing motivation. For example, can students focus on the explanation of writing skills? Can they take notes consciously? Are they interested in outline writing and brainstorming? On the other hand, teacher's guidance to students' writing should be taken into consideration, including writing instructions, oral feedback, and so on.

\section{Questionnaire}

The questionnaire administered in this study consists of three parts. The first part is about personal information; the second part is about students' writing motivation; the third part is about factors that affect learners' motivation to write in English. On the basis of Gardner's (1996) motivation questionnaire table, the questionnaire made some deletions and addition of writing motivation to cater for the research purpose, and a five-point Likert-scale format was adopted to check students' writing motivation. There are 20 items in total in the second and third parts of this questionnaire. The second part of the questionnaire was composed of two types of motivation: intrinsic motivation and extrinsic motivation, 20 items of writing motivations. The third part of the questionnaire was composed of three kinds of motivation factors: teachers, students, and writing environment, 20 motivation factors. The Cronbach alpha reached .832, and KMO reached 0.791 .

\section{E. Interview}

The aim of the interview is to get more detailed information about students' writing motivation and obstacles in the process of English Writing. A semi-structured interview was adopted in this study, and a recorder was used to record the whole process in the interview. Before the interview, researchers should ensure that participants were willing to state their opinions, share their experiences and some privacy. Eight students were chosen to take part in this interview. Questions involved in this interview were adapted from Hadfield Dornyei (2005) study. The interview questions concerned students' motivation and demotivation in the process of English writing. The interview consists of six open-ended questions to allow students to express their ideas based on their own practical situations.

\section{F. Data Collection and Analysis}

Before handing out questionnaires, 40 sophomore clinical majors were selected to participate in a small-scale test to make sure the feasibility and reliability of the study, two weeks later, other 88 students will be involved in the formal study.

The SPSS 19.0 was adopted to analyze the data. In order to make sure the reliability, the Cronbach alpha was used to check the interior consistency of the writing motivation questionnaire.

\section{RESULTS AND DisCUSSION}

\section{A. The Analysis of English Writing Motivation}

The researcher recorded students' writing motivation in the English classes. On the one hand, most students were quiet in writing classes, especially when teachers asked students to express their ideas immediately. However, if teachers rolled names to make students answer questions, they could give some responses. In contrast, if teachers left some time to make students prepare the questions, they would actively answer teachers' questions. When teachers threw a question and asked students to answer it together, most of them could be involved in answering the question. On the other hand, students' writing motivation could be stirred up when the teacher guided students to finish writing tasks step by step. Therefore, teachers can give students some hints to reduce the difficulty of writing and improve students' writing motivation. 
In order to know the overall motivation of clinical majors and what factors could influence their writing motivation, the researcher conducted an analysis of writing motivation.

TABLE 1

DESCRIPTIVE STATISTICS OF WRITING MOTIVATION FOR MEDICAL MAJORS (N=128)

\begin{tabular}{|c|c|c|c|c|}
\hline Motivation & Minimum & Maximum & Mean & SD. \\
\hline Interest & 2.25 & 5.00 & 3.05 & 0.526 \\
\hline Self efficacy & 2.05 & 5.00 & 3.78 & 1.021 \\
\hline Exams (finals and CET-4 or CET-6) & 2.50 & 5.00 & 4.52 & 0.653 \\
\hline Writing contest & 2.50 & 5.00 & 3.75 & 0.525 \\
\hline Desire to go abroad & 2.25 & 5.00 & 3.98 & 1.001 \\
\hline High marks of writing & 2.50 & 5.00 & 4.15 & 0.853 \\
\hline Exchanging ideas & 2.05 & 5.00 & 3.26 & 0.598 \\
\hline Teachers' encouragement & 2.50 & 5.00 & 4.05 & 0.683 \\
\hline Peers' encouragement & 2.50 & 5.00 & 3.94 & 0.586 \\
\hline Writing feedback & 2.25 & 5.00 & 3.97 & 0.701 \\
\hline Teachers' requirement & 2.50 & 5.00 & 4.18 & 1.123 \\
\hline Great achievement & 2.50 & 5.00 & 3.82 & 0.953 \\
\hline A way to facilitate English learning & 2.25 & 5.00 & 3.68 & 0.725 \\
\hline Future job & 2.50 & 5.00 & 3.91 & 0.721 \\
\hline Further study & 2.50 & 5.00 & 3.95 & 0.682 \\
\hline Symbol of high English Proficiency & 2.25 & 5.00 & 3.63 & 0.892 \\
\hline Reinforcement to words and grammars & 2.25 & 5.00 & 3.71 & 0.901 \\
\hline Funny process & 2.50 & 5.00 & 3.22 & 0.633 \\
\hline Stimulus to creative ideas & 2.50 & 5.00 & 3.62 & 0.592 \\
\hline Innovative topics or materials & 2.25 & 5.00 & 3.08 & 1.041 \\
\hline
\end{tabular}

Table 1 shows the minimum, maximum, mean and standard deviation of English writing motivation. The lowest minimum is self-efficacy (2.05), and exchanging ideas (2.05), which can only show a few students lack self-confidence and are reluctant to convey their ideas to their peers. The mean can indicate the overall writing motivation of clinical major students. The higher mean is, the stronger motivation is. From table 1, we find that the motivation dimensions with the highest mean value are exams including finals and CET-4 or CET-6 (4.52), teachers' requirement (4.18), and high marks of writing (4.15), which means most students' writing motivation is positively associated with exams, if students want to get the scholarship, they have to get high scores in English finals. In Zunyi Medical University, the final exams include the term examination and teachers' requirements for the course. For the English course, one of teachers' requirements is about writing: students have to submit at least five papers in Pigai (it is an online platform where teachers can assign the writing task and students can finish the corresponding task) within one term. What's more, passing CET-4 or CET-6 can get extra credits, and it is the standard for students to obtain bachelor degree. In our study, we find high marks of writing can also motivate students' writing. Through our interview, students claimed that if they can get high scores in writing, they can be encouraged to write a good paper to get a higher score in the next writing task. The mean value of encouragement from teachers and peers and teachers' feedback is also higher, which indicates most students hope their writing outcome can be appreciated and recognized by others.

With regard to the future job (3.91) and future study (3.95), the mean values are higher than other items. The reason why students have a stronger motivation for future jobs or studies is that they are clinical majors, and they are probably to be doctors or medical major graduates. Many English writing tasks should be involved in their future jobs or studies, including the abstract of dissertations, thesis to be published in SSCI, and so on. In the interview, seven out of eight students told that they felt nervous about their futures, and two of them showed that they wanted to study abroad to keep work on their profession, but they need to sharpen their English writing skills in order to achieve such more writing tasks in the university of foreign countries.

In contrast, the motivation dimensions with the lowest mean value are writing interest (3.05) and innovative topics and materials (3.08), which suggests that writing is a tough and boring task which needs to be paid more time and energy. Writing is regarded as a painful process by most students, even if more efforts are paid, few harvests can be reaped. That's the reason why students have less interest in writing, even some innovative writing tasks cannot stimulate students' motivation to practice the writing.

B. Analysis of Writing Motivation Factors 
TABLE 2

DESCRIPTIVE STATISTICS OF FACTOR QUESTIONNAIRE ITEMS

\begin{tabular}{llllll}
\hline Item & Mean & SD. & Item & Mean & SD. \\
\hline 1 & 3.209 & 0.932 & 11 & 2.398 & 3.676 \\
2 & 2.256 & 0.622 & 12 & 1.779 & 0.772 \\
3 & 2.687 & 0.732 & 13 & 1.990 & 0.688 \\
4 & 3.056 & 0.866 & 14 & 2.223 & 0.945 \\
5 & 2.389 & 0.989 & 15 & 2.543 & 1.105 \\
6 & 1.326 & 1.290 & 16 & 1.270 & 0.732 \\
7 & 2.765 & 0.778 & 17 & 1.895 & 1.121 \\
8 & 2.489 & 0.883 & 18 & 0.654 \\
9 & 2.337 & 0.913 & 19 & 2.552 & 0.832 \\
10 & 1.982 & 0.843 & 20 & 1.906 & 0.787 \\
\hline
\end{tabular}

TABLE 3

RESULTS OF FACTOR RELIABILITY

\begin{tabular}{ccccc}
\multicolumn{5}{c}{ RESULTS OF FACTOR RELIABILITY } \\
\hline Factor & Teachers' guidance & Writing interest & Writing proficiency & Writing environment \\
\hline Reliability & 0.87 & 0.75 & 0.85 & 0.81 \\
\hline
\end{tabular}

Table 2 illustrates questionnaire items of writing motivation. We can see the mean values of three items are above 3 , they are item 1 (3.209), item 4 (3.056), and item 12 (3.676), two of which are concerned about teachers. And it proves that teachers' roles are essential in students' English writing. The highest item is scores, and it shows that students are expecting good results of writing. In fact, they also want to be praised by teachers.

Table 3 shows that the data is suitable for factor analysis (KMO=0.86; the result is significant). The direct Oblimin is adopted to categorize the motivation factors into four kinds. The interval of four factors is from 0.75 to 0.87 , with a high reliability coefficient, and the internal consistency is high.

According to tables 2 and 3, it is obvious that teacher's attention to students will greatly enhance students' writing motivation under the circumstance where self-study is the main way of learning in the university.

TABLE 4

WRITING MOTIVATION FACTOR ANALYSIS

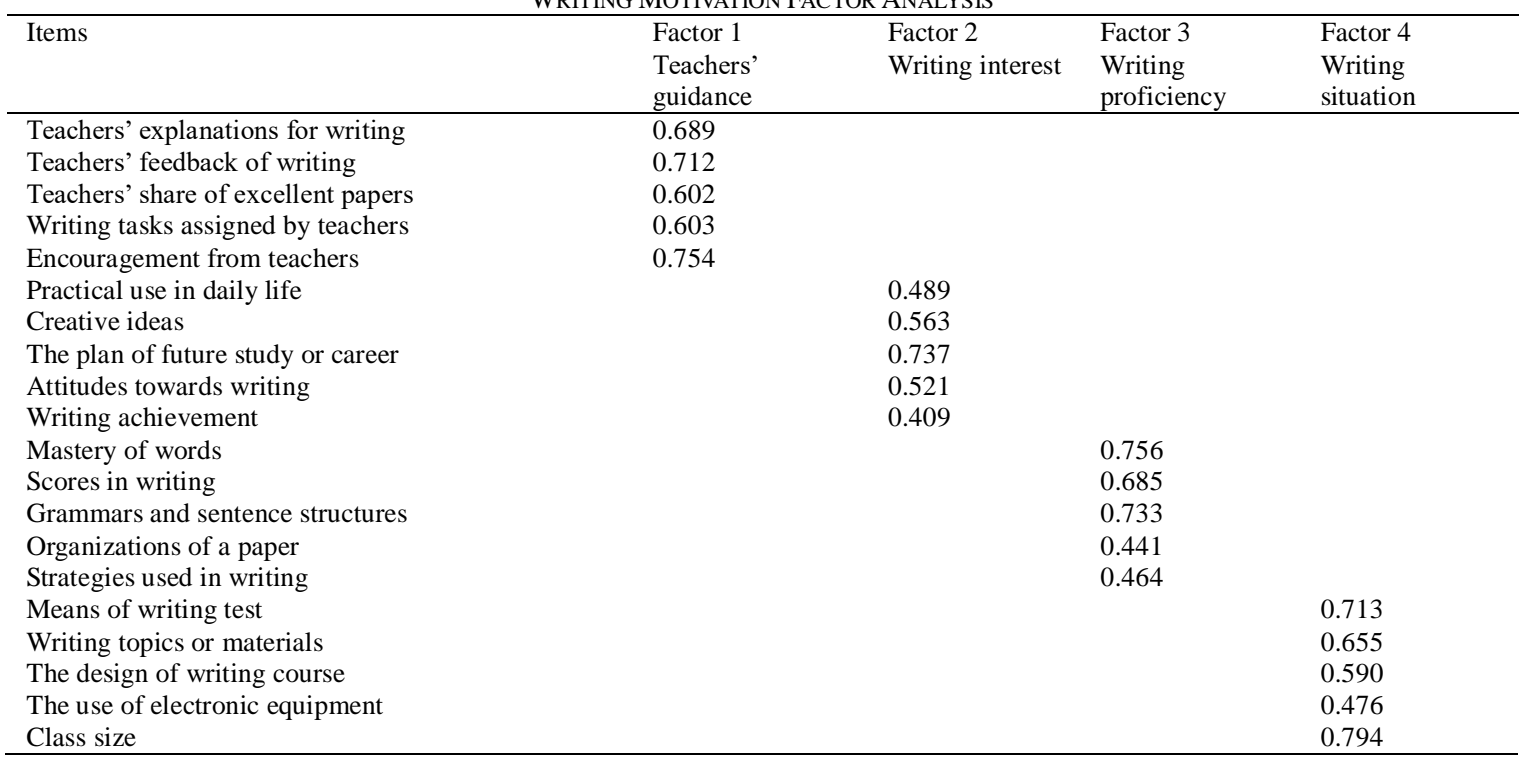

As illustrated in table 3 , the factor 1 is about teachers' influence on students' writing motivation; the factor 2 and factor 3 are concerned with students themselves, and they are regarded as the intrinsic motivation factors; the factor 4 is associated with writing environment, including practical writing situation, auxiliary writing equipment, and writing materials. Therefore, the factor 1 and factor 4 can be taken as the extrinsic motivation factors. The result is consistent with Yin's study (2016) which reveals that motivators in college students' English learning involve four aspects: teacher, student, environment, and teaching materials, of which teacher and student are two main factors.

With respect to the factor 1, we find that teachers' guidance plays a critical role in exploring students' writing motivation. Teachers' encouragement and feedback significantly impact students' writing motivation. A large class size may make it hard for teachers to build a close relationship with their students. In this case, teachers' encouragement may help to build such a relationship because students may feel that teachers are paying attention to them. For the factor 2, we can see that the overall level of writing interest is low, because there are less requirements and no practical use for English writing, and students are unaware of the purpose of writing. However, the plan of future study or career is higher than other items of writing interest, because they are medical majors. Whether they want to continue to study medicine or choose a doctor as their profession in the future, English learning is a must, and English writing plays a 
significant role in their future learning or career. The factor 3, writing proficiency, also occupies an important position. Starting from learning English, words, grammar, and sentence structures are always the focus for students to learn. Most students write for high scores due to the exam-oriented education. As for the factor 4, class size and means of test play a crucial role in writing motivation. In a large class, teachers cannot keep a watchful eye on every individual, and some students who lack the ability of self-learning and self-discipline may gradually lose writing motivation without supervision. What's more, teachers may neglect what obstacles appear in students' writing, and they cannot give students suitable suggestions, and this cycle greatly weakens students' enthusiasm to engage in writing tasks.

\section{The StRATEgIES TO IMPROVE WRITING MOtIVATION}

Based on the observation and interview, we find that students' writing motivation is not high, and there is no clear goal to write a paper. What's more, they cannot use efficient strategies to solve the obstacles in the process of writing. Therefore, some advice can be come up with to serve as stimulating students' writing motivation and improving language proficiency.

\section{A. Teachers' Influence on Students 'Writing Motivation}

Dornyei (2001) induces nine types of demotivating factors, and the first factor is the teacher, including teachers' personality, characters, ability, skills, and teaching methods. There are many studies focusing on motivation at home and abroad, and researchers find the factors that influence students' writing motivation involve intrinsic and extrinsic factors, but the teacher is the key factor.

\section{Explanations of Writing Strategies}

Writing strategies will help facilitate writing, reduce anxiety, and boost motivation. Students may use their writing strategies, but they really desire teachers' explanations of writing strategies. In our class observations, all students are absorbed in teachers' writing explanations. They take notes carefully, and actively think and answer questions. Therefore, teachers' explanation of writing strategies is an efficient way to enhance students' writing motivation.

\section{a. "Scaffolding" Strategy}

"Scaffolding" strategy will help students to conceive or write an outline of a paper, which is a feasible way to improve students' writing ability and cope with the situation where students do not know how to organize the paper. For a normal paper, the scaffold is "head-body-tail". "Head" means an introduction of a paper, and it only offers the general concept or idea rather than details. So in this part, the writer's opinion should be presented clearly. "Body" part should provide more details to support the writer's opinion. "Tail" part will show the summary of the whole passage, and appeals, suggestions, or expectations should follow the conclusion. Therefore, when students keep this structure in their minds, the writing task tends to be easy and efficient.

\section{b. Brainstorming Strategy}

Brainstorming is another effective strategy to improve students' writing motivation, especially for students with a lower level of language proficiency. However, this strategy should be conducted by teachers in the class. Teachers will cast out a topic first, then students should try their best to output more creative ideas within a limited time. Students have to concentrate fully on thinking in this process in order to produce more ideas. When new ideas are poured out, students' motivation can be greatly reinforced. Therefore, Thinking out creative ideas is the preliminary step in the whole writing process.

\section{Teachers' Feedback}

Teachers' feedback is undoubtedly the most effective way to boost students' writing motivation, especially in the university where students and teachers rarely communicate with each other. There are mainly two ways to give students feedback on writing: The first way is to comment on students' writing papers directly. Teachers can mark errors, good sentences, or inappropriate expressions on the paper directly. Meanwhile, teachers can write down suggestions about merits and shortcomings on the margin of a paper. Besides, teachers can give a general comment at the end of a paper, including the organization of the paper, writing skills, and some encouraging words, which can push students to improve their writing from many aspects. Another way is the one-on-one writing conference. It can personalize and tailor feedback in a way that may not happen in a regular class. It also can avoid misunderstandings when giving students feedback on the paper. Although this way may ask teachers to invest more time and energy, it is indeed helpful to boost students' writing motivation. Based on our interview, seven out of eight students get benefits from face-to-face interaction, and they hope more chances can be offered to interact with their teachers about their writing. Face-to-face interaction enables students to safely and thoroughly communicate with their teachers about their writing. In the feedback process, teachers can give detailed explanations about their writing, and students feel relaxed to exchange ideas with teachers. When they have some questions or doubts about teachers' advice on the writing, they can talk to teachers immediately. After the teachers' feedback on the writing, students may show their anxiety or problems when they are writing papers, and teachers can give corresponding solutions to relieve students' stress and nervousness. It helps students to build the confidence to work on the writing task. Furthermore, a good relationship is established 
between students and teachers in this negotiating process, and students' writing motivation can be evoked based on the harmonious relationship.

\section{B. Interesting Writing Task}

When students' writing motivation is low, funny writing tasks can be adopted to heighten motivation. From the psychological angle, we found that these tasks played indispensable roles in the improvement of students' writing performance as students in this study claimed that they were more likely to engage in a writing task when they were interested in it. One of the interviewees expressed that she liked writing because an interesting task really motivated her and helped her keep a writing habit. Her teacher asked her to write down what she thought and felt on post-it notes and shared it with her roommates. She can put the written post-it notes on the door or closet, and everyone in the dormitory can read the notes together. Another interviewee from the same dormitory articulated the reason why she liked this way because they feel free to write in English, and there was no any burden or pressure to do this task. Therefore, this writing task changed from a task that the teacher demands to finish to a task that students volunteer to do without teachers' requirements.

\section{Optimization of Writing Environment}

English writing obtains dual attributes of emotion and cognition. A fitting writing environment, although as an extrinsic motivation factor, also dramatically makes students emotionally rather than anxiously. Therefore, teachers can nudge students' writing motivation from the writing environment through teaching methods and strategies.

\section{Online Writing Environment}

Online writing can provide a new environment for students to work on writing task. Compared to paper writing, online writing can create real situations to arouse authentic writing. E-mail is a popular way to communicate in writing online; students can exchange ideas with their friends and teachers by using the e-mail. In the process of writing the e-mail, students' writing motivation can be stirred up because of the true purpose of writing and expectations for the response. As such, e-mail provides a social experience instead of a solely linguistic perspective. For another, writing online can offer chances for independent writing. According to our interview, many students get benefits from online writing, and they enjoy this way to write the composition. It is an efficient way to give students prompt feedback about mistakes in the writing, including sentence structures, grammar, and improper expressions, meanwhile, the merits will be pointed out as well. On the other hand, the score is an item of feedback, and it is really a fantastic way to enhance motivation for most students. The high score can be a stimulus to push students to sharpen their writing skills, think of more creative ideas and organize the whole paper logically; the low score can remind that students' writing ability should be elevated, which makes students feel a sense of urgency to better their writing proficiency.

\section{Cooperative Writing Environment}

Writing is an activity associated with psychology, cognition, thinking, and communication. Collaborative writing environment will make students feel at ease when facing the writing task. Writing is regarded as a social activity because the revision, feedback, and review of a paper can be a process of social interaction, and it needs to be accomplished by students as a group. Based on the class observation, we can find there is a relaxed and harmonious atmosphere when group members are discussing the writing assignment, and everyone is eager to participate in this activity. The writer in the group can express his own ideas while others in this group can analyze the paper and point out the advantages or flaws of the paper. In turn, the writer can modify the paper based on group members' suggestions. In such a cooperative environment, students can relieve nervousness and anxiety to the greatest extent, which urges them to take part in the writing activity, and participants can show their high motivation in the cooperative writing environment.

\section{Pedagogical Implications And Conclusions}

The study explored the reasons why students lack motivation in English writing. Although English writing is not the most difficult part of English learning, and it is not regarded as the most important aspect in an English test, English writing is crucial for medical majors. To improve students' writing motivation becomes an urgent and arduous task for a university English teacher.

From the perspective of psychological linguistics, the author finds that students' writing motivation is bound up with their feeling, mood, and mentality. According to the results of our research, the author puts forward available strategies to optimize students' mindsets and raise their intrinsic writing motivation. Medical majors are a special group because they have to endure a longer learning period, heavier learning burden, greater learning pressure, and higher requirements for academic writing. They are easy to neglect English learning under such a circumstance, let alone English writing. Although it's difficult for teachers to cultivate students' writing motivation, they should endeavor to devise effective methods to stimulate students' interest in writing. At first, a more relaxed and pleasurable writing atmosphere can be created by teachers, which requires teachers to know their personality, mood, and psychology well. Then diversified tasks can be assigned to students, and it also needs teachers to know students' writing levels. Besides, detailed feedback should be given to students, which claims teachers to spend more time and energy in reading students' 
compositions. Finally, teachers should lead students to set a reasonable writing goal, because a reasonable goal can enhance students' writing efficiency and efficacy.

\section{A. Research Findings}

Based on the quantitative research, the following two major findings can be summed up:

From the interview, we find that most clinical majors do not view English as an important subject, not speak of English writing. There are mainly three reasons: Firstly, most students attach importance to their medical subjects. When they choose medicine as their major, they have already determined to be a doctor in the future. Therefore, they spend more time in studying their medical majors, and less time can be spent on English learning when an English test approaches. Secondly, there is no special English writing course for non-English majors, and teachers do not want to spend more time on writing explanations. Students do not know what the real goal of writing is, and most students take the writing examination as the ultimate goal. Thirdly, the writing part occupies a low percent in many important English tests, like CET-4 or 6 . Since many students take the examination as a way to strengthen their writing motivation, however, the writing part of CET-4 examination (the most important English test for non-English majors) only occupies $15 \%$ while the reading part and listening part occupy $35 \%$ respectively. Therefore, most students want to spend more time in doing reading and listening exercises.

Through the questionnaire data, we can conclude that students' motivation can be aroused by teachers. Teachers' focuses on English writing have a great impact on students' motivation of writing. In our interview, one of the interviewees expressed that teachers rarely told them the importance of writing, and they knew few strategies when they were going to write a composition. Even if they finished online writing tasks, less feedback could be got from teachers. In fact, students are eager to get teachers' feedback as long as they hand in the writing papers.

\section{B. Implications for Teachers}

Our study shows that teachers play a significant role in the enhancement of students' writing motivation. Therefore, the findings of the studies seem to have important implications for college English teachers and language researchers. For one thing, teachers should care about students' psychological status, because their writing motivation is closely related to their mindset. How can make students finish the writing task with a positive attitude and relaxed feeling? Teachers' praises are undoubtedly the first choice. When teachers read the paper, they can try their best to find more merits in the paper; even in the one-on-one interaction, inspirational words can be conveyed to students, which encourage them to write more excellent papers. For another, teachers can design different activities to boost writing motivation for students of different proficiency. Higher proficiency students tend to practice more academic writing instead of three-paragraph writing in CET-4 or 6 . The writing task should involve more research, and students have to refer, gather, and generate information before writing. For example, writing the outline, abstract, summary is an appropriate task for higher-level students. On the contrary, such tasks cannot be assigned to lower proficiency students in that difficult tasks will bring more burden and pressure to students, which will reduce the interests and motivation of writing.

\section{Limitations of the Present Study and Suggestions for Further Study}

After discussing the implications of the study, it is important for the researcher to outline the shortcomings and deficiencies of the study. Suggestions will be given based on the limitations.

Firstly, the research tools of this study are class observation, a questionnaire, and a semi-structured interview. The questionnaire requires students to write down their real names, so some students may have some concerns and not give truthful answers. The face-to-face interview only involves eight students, the sample we choose to take part in the interview is small, and they cannot represent all participants' ideas, meanwhile, when they communicate with the researcher, they may feel nervous, which may result in less objective results. Therefore, students can write their aliases on the questionnaire to make sure the authenticity and objectivity of the questionnaire. In addition, more participants can be involved in the interview, and more detailed questions can be designed to explore more factors that are associated with writing motivation.

Secondly, the sample size we choose is relatively small; all participants are medical majors and could not stand for the whole non-English majors. Meanwhile, all participants involved in this research are from a university, which is from a single source. Further studies should expand the number of participants, and students should be selected from different majors, colleges as well as regions as participants.

Finally, this study only concentrates on students' writing motivation and factors that can influence writing motivation rather than taking the relationship between motivation and writing achievement into account. Although at the end of the paper, the author poses some strategies to heighten writing motivation, there is no correlation analysis to show the relationship between writing strategies and motivation. So future studies can also be focused on writing strategies and use diverse analytical methods to get the deeper research results.

\section{REFERENCES}

[1] Ainley, M. (2012). Students' Interest and Engagement in Classroom Activities. In S. L. Christenson, A. L. Reschly, \& C. Wylie (Eds) . Handbook of Research on Student Engagement. 283-302. 
[2] Dornyei, Z. (2001). Motivational Strategies in the Language Classroom. Cambridge: Cambridge University Press.

[3] Dornyei, Z. \& K. Csizer. (2002). Some Dynamics of Language Attitudes and Motivation: Results of a Longitudinal Nationwide Survey. Applied Linguistics. (23/4): 421-426.

[4] Dornyei, Z. (2003). Attitudes, Orientations, and Motivations in Language Learning: Advances in Theory, Research, and Applications. Language Teaching, Supplement. (1): 3-32.

[5] Dornyei, Z. (2005). The Psychology of Language Learner: Individual Differences in Second Language Acquisition. NJ: Lawrence Erlbaum Associates. 18, 146.

[6] Dornyei, Z. (2009). The Second Language Motivational Self System. In Dornyei, Z. \&E. Ushioda (Eds.). Motivation, Language Identity and the L2 Self . Bristol: Multilingual Matters. 12, 9-42.

[7] Gardner, R. \& W. Lambert. (1972). Attitudes and Motivation in Second Language Learning. Rowley, MA: Newbury House.

[8] Gao, Y.H., Zhao, Y., Chen, Y. \& Zhou, Y. (2003). Research on Types of English Learning Motivation for College Students. Modern Foreign Languages. (01): 51-58

[9] Gumming, A. (1989). Writing Expertise and Second Language Proficiency. Language Learning. 30, 38-39.

[10] Manolopoulou-Sergi, E. (2004). Motivation within the Information Processing Model of Foreign Language Learning. System. 32(3), 427-441.

[11] Ma, G. H., \&Wen, Q. F. (1999). The Relationship of L2 Learners' Linguistic Variables to L2 Writing Ability. Foreign Language Teaching and Research. (04): 34-39.

[12] Ma, G. H. (2005). The Effect of Motivation and Efforts on Foreign Language Achievement. Journal of PLA University of Foreign Languages. (04): 37-41.

[13] Mu, Congjun. (2005). A Taxonomy of ESL Writing Strategies. Redesigning Pedagogy: Research, Policy, Practice. (05): 7-10.

[14] Qing X. Q. (2002). The Significance of Motivation Theory on Foreign Language Learning. Foreign Language Research. (04): 74-79.

[15] Reeve, J. (2012). A Self-determination Theory Perspective on Student Engagement. In S. L. Christenson, A. L. Reschly, \& C. Wylie (Eds). Handbook of Research on Student Engagement. (05):149-172.

[16] Ren, F. L. (2018). The Research on Chinese College Students' Writing Motivation. Journal of Hefei Normal University. (03):118-122.

[17] Strayer, J. F. (2012). How Learning in an Inverted Classroom Influences Cooperation, Innovation and Task Orientation. Learning Environments Research. 15(2):171-193

[18] Wen, Q.F. (2001). Applied Linguistics: Research Methods and Thesis Writing. Beijing: Foreign Language Teaching and Research Press.

[19] Yin, H., \& Wang, W. (2016). Undergraduate Students' Motivation and Engagement in China: An Exploratory Study. Assessment and Evaluation in Higher Education. 41, 601-602.

[20] Yu, S., \& Lee, I. (2016). Peer feedback in Second Language Writing (2005-2014). Language Teaching. 49(4), 461-493.

[21] Zheng, X., Yin, H., \& Wang, M. (2018). Leading with Teachers' Emotional Labour: Relationships between Leadership Practices, Emotional Labour Strategies and Efficacy in China. Teachers and Teaching Theory and Practice. 24, 965-979.

Yingying Ma was born in Guizhou Province, China in 1981. She finished his MA in Foreign and Applied Linguistics in Guizhou University, China in 2013. She has embarked on English teaching for 17 years. She is an associate professor in English Teaching at Zunyi Medical University. Her research field mainly focuses on second language teaching and second language acquisition. 